\title{
A label-free biosensor based on graphene and reduced graphene oxide dual-layer for electrochemical determination of beta-amyloid biomarkers
}

\author{
Jagriti Sethi $^{1}$ (D) $\cdot$ Michiel Van Bulck ${ }^{2,3} \cdot$ Ahmed Suhail $^{1} \cdot$ Mina Safarzadeh $^{1} \cdot$ Ana Perez-Castillo $^{2,3} \cdot$ Genhua Pan $^{1}$
}

Received: 2 November 2019 / Accepted: 10 April 2020 /Published online: 25 April 2020

(C) The Author(s) 2020, corrected publication 2020

\begin{abstract}
A label-free biosensor is developed for the determination of plasma-based $A \beta_{1-42}$ biomarker in Alzheimer's disease (AD). The platform is based on highly conductive dual-layer of graphene and electrochemically reduced graphene oxide (rGO). The modification of dual-layer with 1-pyrenebutyric acid $N$-hydroxysuccinimide ester (Pyr-NHS) is achieved to facilitate immobilization of H31L21 antibody. The effect of these modifications were studied with morphological, spectral and electrochemical techniques. The response of the biosensor was evaluated using differential pulse voltammetry (DPV). The data was acquired at a working potential of $\sim 180 \mathrm{mV}$ and a scan rate of $50 \mathrm{mV} \mathrm{s}^{-1}$. A low limit of detection (LOD) of $2.398 \mathrm{pM}$ is achieved over a wide linear range from $11 \mathrm{pM}$ to $55 \mathrm{nM}$. The biosensor exhibits excellent specificity over $\mathrm{A} \beta_{1-40}$ and ApoE $\varepsilon 4$ interfering species. Thus, it provides a viable tool for electrochemical determination of $A \beta_{1-42}$. Spiked human and mice plasmas were used for the successful validation of the sensing platform in bio-fluidic samples. The results obtained from mice plasma analysis concurred with the immunohistochemistry (IHC) and magnetic resonance imaging (MRI) data obtained from brain analysis.
\end{abstract}

Keywords Graphene $\cdot A \beta_{1-42}$ detection $\cdot$ Alzheimer's disease $\cdot$ Electrochemical biosensors $\cdot$ Screen-printed electrodes

\section{Introduction}

The current trend in the realm of medical science is to investigate the molecular basis of ailments as opposed to following a symptomatic approach. This has prompted remarkable improvements in research for chronic ailments such as Alzheimer's disease (AD). Abnormal levels of certain biomarkers in bio-fluids have been associated with $\mathrm{AD}$

Electronic supplementary material The online version of this article (https://doi.org/10.1007/s00604-020-04267-x) contains supplementary material, which is available to authorized users.

Jagriti Sethi

jagriti.sethi@plymouth.ac.uk

1 Wolfson Nanomagnetics Laboratory, School of Engineering, Computing and Mathematics, University of Plymouth, Devon PL4 8AA, UK

2 Instituto de Investigaciones Biomédicas (CSIC-UAM), Arturo Duperier, 4, 28029 Madrid, Spain

3 Centro de Investigación Biomédica en Red sobre Enfermedades Neurodegenerativas (CIBERNED), Valderrebollo, 5, 28031 Madrid, Spain progression [1]. One such biomarker is beta-amyloid $(A \beta)$ peptide consisting of 40 and 42 amino acids, namely $A \beta_{1-40}$ and $A \beta_{1-42}$. Their abnormal levels in bio-fluids have been correlated with amyloid pathology in AD-affected brain [2]. The continuous monitoring of $A \beta$ levels could provide aid in early diagnosis, before the onset of symptoms [3]. As a result, several platforms including enzyme-linked immunosorbent assay (ELISA) [4], surface-enhanced spectroscopy (SERS) [5], surface plasmon resonance (SPR) [6], electrochemical sensors [7-9] and field effect transistors [10] have been developed. Among these, electrochemical sensors are most attractive and, therefore, widely preferred. This is attributed to various merits such as high sensitivity [3], possibility of label-free sensing, portability [11], simplicity of apparatus and easy handling [9]. However, electrochemical platforms developed for $\mathrm{A} \beta_{1-42}$ detection have shown various limitations. These include lack of bio-fluid analysis, low sensitivity and nonspecific bindings particularly with $\mathrm{A} \beta_{1-40}[12]$.

An interdigitated microelectrode system was recently developed for the detection of $A \beta_{1-42}$. The electrode was used alongside a signal cancellation and amplification processing system (SCAP) [3]. The platform was validated with mice plasma samples. Despite excellent sensitivity, use of an 
additional SCAP system makes the platform more complex and expensive. The specificity of the sensor is also questionable towards $A \beta_{1-42}$ in the presence of interfering $A \beta_{1-40}$ and ApoE species [13]. Another biosensor based on gold (Au) electrode and mercaptopropionic acid self-assembled monolayer (SAM) reported high sensitivity [2]. However, the platform failed to depict specificity against any interfering species present in the complex bio-fluids. With $\mathrm{A} \beta_{1-42} / \mathrm{A} \beta_{1-}$ 40 ratios gaining interest as a potential biomarker, reliable detection of individual biomarker is more important than ever $[14,15]$. In addition, deposition of $A \beta_{1-42}$ starts earlier compared with $A \beta_{1-40}$ during $A D$ progression [16]. The interference with $A p o E \varepsilon 4$ species can also prompt false results when analysing $A \beta_{1-42}$ in patients' samples. This is due to the fact that $\mathrm{ApoE} \varepsilon 4$ can be present in up to 10,000 -fold excess in human plasma [17]. Therefore, specific determination of $A \beta$ biomarkers is an important prerequisite for bio-fluid analysis and understanding $\mathrm{AD}$ progression.

Graphene is a widely investigated material due to its remarkable properties such as high conductivity, biocompatibility, ease of surface functionalization [18], large surface to volume ratio and low environmental impact [19]. Graphenebased biosensors can detect extremely low concentration of biomarkers [1]. This is attributed to the fact that presence or absence of a very few analyte molecules can trigger a recognizable change in electrical properties of graphene. Another material which is widely preferred for biosensors is reduced graphene oxide (rGO). It has structural similarities to graphene with large number of electroactive sites providing highly sensitive material for sensing [18]. Most of the graphene-based biosensors are based on either only graphene [20] or only rGO [21]. A combination of the two materials for the detection of protein biomarkers is yet to be explored. The conductivity of rGO on graphene is much higher than on other materials such as carbon [22]. Coupling of rGO and graphene provides high conductivity with large number of available active sites which can be useful for biosensing. The rGO surface can be chemically functionalized to anchor antibodies on the surface [23] which can be achieved by covalent or noncovalent modifications. The covalent modification may damage and degrade the properties of rGO [24]. Therefore, noncovalent modification methods are a preferred choice. 1Pyrenebutyric acid $N$-hydroxysuccinimide ester (Pyr- NHS) is a bi-functional molecule which binds non-covalently to graphene and carbon surfaces $[25,26]$. It promotes strong immobilization of antibodies without any adverse effect on the underlying structure. This has shown to improve sensitivity for detection of clusterin, another well-known biomarker of $\mathrm{AD}$ [25]. Thus, Pyr-NHS is an excellent linker for the immobilization of probes on the graphene biosensors.

In the present work, graphene/rGO dual-layer screenprinted electrode (SPE) is developed for rapid, label-free and reliable detection of $A \beta_{1-42}$. Higher redox current is observed for dual-layer SPE, confirming its improved sensitivity compared with only graphene and graphene/GO SPE. The immobilization of H31L21 antibody achieved via Pyr-NHS leads to high specificity of the biosensor towards $A \beta_{1-42}$ peptides without damaging underlying $\mathrm{rGO}$ structure. The interaction of Pyr-NHS with rGO on a dual-layer surface is reported for the first time. The platform shows wide linear dynamic range with low detection limit. To the best of our knowledge, this is the first report of a biosensor depicting specificity against $\mathrm{A} \beta_{1-40}$ and $\mathrm{ApoE} \varepsilon 4$ interfering species as well as high sensitivity. The biosensor has been successfully validated with both spiked human and mice plasma samples. Detailed comparison of dual-layer SPE over the existing label-free biosensors are made in Table 1.

\section{Experimental}

\section{Reagents and animals}

Single-layer graphene oxide dispersion in water was purchased from Graphene Supermarket (USA) (https:// graphene-supermarket.com/). Chemicals such as bovine serum albumin (BSA), 1-pyrenebutyric acid $N$ hydroxysuccinimide ester (Pyr-NHS), phosphate buffered saline (PBS), human plasma, $A \beta_{1-42}$ peptides, potassium ferricyanide $\left(\mathrm{K}_{3} \mathrm{Fe}(\mathrm{CN})_{6}\right)$ and potassium chloride $(\mathrm{KCl})$ at biochemical grade were purchased from Sigma-Aldrich (Dorset, UK) (https://www.sigmaaldrich.com/united-kingdom.html). $\mathrm{A} \beta_{1-42}$ antibody (H31L21), 4',6-Diamidino-2-Phenylindole (DAPI) and Alexa Fluor 546 goat anti-rabbit secondary antibody were provided by Thermo Fisher Scientific (https:// www.thermofisher.com/uk/en/home.html). $\mathrm{A} \beta_{1-40}$ and ApoE $\varepsilon 4$ peptides were obtained from Tocris (UK) (https:// www.tocris.com/). Paraformaldehyde (PFA) was purchased from Merck (Spain) (https://www.merckgroup.com/es-es). Sucrose, Triton X-100 and Eppendorf ${ }^{\circ}$ LoBind Microcentrifuge Tubes were obtained from Sigma-Aldrich (Spain) (https://www.sigmaaldrich.com/spain.html). Normal Goat Serum (NGS) and Vectashield H-1200 were provided by Vector Laboratories (Spain) (https://vectorlabs.com/). Microvette ${ }^{\circledR}$ CB $300 \mathrm{~K} 2 \mathrm{E}$ tubes were obtained from Sarstedt (Spain) (https://www.sarstedt.com/en/home/).

Blood and brain samples were obtained from 9 and 12 months old wild-type (WT) and transgenic (Tg) animals of the strain B6.Cg-Tg (APPswe/PSEN1dE9) 85Dbo/Mmjax, Lab Stock\# 005864. All the experiments related to the animals were performed in the Centro de Investigación Biomédica en Red Enfermedades Neurodegenerativas (CIBERNED), Spain. The ethical approval was provided by the "Ethics Committee for Animal Experimentation" of the Instituto de Investigaciones Biomédicas (CSIC-UAM) and experiments were carried out in accordance with European Communities 
Council Directive (2010/63/EEC) and National regulations (Normative 53/2013).

Plasma studies with biosensors were performed in the University of Plymouth, UK, with approval of Local Ethics Committee.

\section{Apparatus}

Graphene-modified SPEs and $\mu$ Stat potentiostat were provided by Metrohm DropSens (UK). The electrode had graphene as working, carbon as an auxiliary and silver as a reference electrode. Electrochemical cyclic voltammetry $(\mathrm{CV})$ and differential pulse voltammetry (DPV) measurements were performed at room temperature with a $\mu$ Stat potentiostat. The experiments were controlled using DropView 84002.0 software. The $\mu$ Stat cable connector (ref. DRP-CAST) was used as an interface between the potentiostat and SPEs.

Raman spectra were obtained using XPLORA HORIBA system and Olympus BX41 microscope. The system used a 532-nm laser source, power of $100 \mathrm{~mW}, \times 100$ objective lens, a scan range of 1100 to $2000 \mathrm{~cm}^{-1}$ and an exposure time of 5-60 s.

Immunofluorescence data was collected using a Nikon Eclipse 90i microscope using Plan APO 4x objective, equipped with Nikon DS-Fil digital camera. It was connected to Nis-Elements software (Madrid, Spain).

Magnetic resonance imaging (MRI) was performed on a Bruker Pharmascan Biospect system (Bruker Medical Gmbh, Ettlingen, Germany). The system was equipped with a 7.0-T horizontal-bore superconducting magnet, ${ }^{1} \mathrm{H}$ receive-only mouse brain surface coil and volume transmission coil and a Bruker gradient insert (maximum intensity $36 \mathrm{G} \mathrm{cm}^{-1}$ ). All data was acquired using a Hewlett-Packard console running on Paravision 5.1 software (Bruker Medical Gmbh, Germany). Sensor with monitor system (SA Instruments, Stony Brook, $\mathrm{NY}$ ) was used to measure the rate and depth of respiration.

The Thermo Scientific ${ }^{\mathrm{TM}} \mathrm{Nexsa}^{\mathrm{TM}}$ system was used for carrying out the X-ray photoelectron spectrum (XPS) analysis. The morphological analysis was done with JEOL 6610 LV scanning electron micrscope (SEM) from Oxford Instruments.

\section{Fabrication of biosensor}

The graphene/rGO dual-layer SPE was prepared using the protocol mentioned in our previous work [18]. Briefly, an aqueous solution of $0.15 \mathrm{mg} \mathrm{mL}^{-1} \mathrm{GO}$ was prepared in deionized (DI) water. The solution was then carefully drop casted onto the surface and dried for $2 \mathrm{~h}$ at room temperature. This promotes strong bond formation of GO on graphene SPE. After that, the SPE was washed 3 times with DI water. GO layer was then electrochemically reduced in 10 $\mathrm{mM} \mathrm{K}_{3}\left[\mathrm{Fe}(\mathrm{CN})_{6}\right]$ containing $1 \mathrm{M} \mathrm{KCl}$ solution by one $\mathrm{CV}$ cycle. A scan rate of $100 \mathrm{mV} \mathrm{s}^{-1}$ was applied, and potential was varied between 0.5 and $-1.5 \mathrm{~V}$ [18]. In the next step, the 
dual-layer SPE was incubated in $5 \mathrm{mM}$ Pyr-NHS (in methanol) for $2 \mathrm{~h}$ at room temperature. Subsequently, it was incubated overnight $(16 \mathrm{~h})$ in $20 \mu \mathrm{g} \mathrm{mL}^{-1}$ of $\mathrm{A} \beta_{1-42}$ antibody (H31L21) at $4{ }^{\circ} \mathrm{C}$. Then, electrodes were rinsed with PBS to remove any unbound antibody. This was followed by blocking of the surface with $2 \%$ BSA (in PBS) for $2 \mathrm{~h}$ at room temperature. The schematic representation of the fabrication process is described in Fig. 1.

\section{Interaction of $A \beta_{1-42}$ with the sensor}

The desired dilutions of $\mathrm{A} \beta_{1-42}$ peptides $(0.2 \mathrm{pM}$ to $55 \mathrm{nM})$ were freshly prepared in PBS by sonication for $2 \mathrm{~min}$. The prepared peptides were kept on ice during the experiments to avoid their aggregation. Then, $20 \mu \mathrm{L}$ of solution was drop casted onto the modified SPE and incubated at room temperature for $60 \mathrm{~min}$. After that, the sensor was washed 3 times before the measurements to remove any unbound peptide. The measurement time for one sensor is approximately 3-4 min.

\section{Blood sampling method}

Blood was drawn by submandibular bleeding methods using a sterile blood lancet [29]. The blood droplets were collected by Microvette ${ }^{\circledR}$ CB 300 K2E tubes. A novel standardized method of blood extraction and purification protocol was developed to obtain non-haemolytic plasma samples from rodents. It consisted of two centrifuge steps. The first centrifuge step $\left(1500 \times g\right.$ for $10 \mathrm{~min}$ at $15^{\circ} \mathrm{C}$ ) was performed soon after the blood collection, to separate the plasma fraction from red blood cells and buffy coat. Then, the plasma fraction was collected in Eppendorf® LoBind Microcentrifuge Tubes and directly placed on ice. The second centrifuge step $(3500 \times \mathrm{g}$ for $10 \mathrm{~min}$ at $4{ }^{\circ} \mathrm{C}$ ) was carried out to separate additional red blood cell debris. Finally, the plasma was divided in aliquots and stored at $-80^{\circ} \mathrm{C}$ for long-term preservation.

\section{Plasma sample analysis}

Dual-layer SPE was validated with both mice and human plasma. The plasma from human was spiked with desired concentration of $A \beta_{1-42}$. Then, $20 \mu$ of spiked plasma was drop casted on to the biosensors for $60 \mathrm{~min}$. Mice plasma samples were analysed in a similar way without any pretreatment.

\section{Electrochemical detection}

All the measurements were carried out in an electrolyte solution containing $10 \mathrm{mM}$ potassium ferricyanide solution with $1 \mathrm{M} \mathrm{KCl}$ as the supporting electrolyte. $\mathrm{CV}$ was recorded from -0.2 to $+0.5 \mathrm{~V}$ potential and $0.05 \mathrm{~V} \mathrm{~s}^{-1}$ scan rate without the application of any preconditioning potential or accumulation time. For DPV, potential was measured from -0.15 to + $0.45 \mathrm{~V}$ with a step potential of $0.01 \mathrm{~V}$, pulse amplitude of $0.05 \mathrm{~V}$, pulse period of $0.4 \mathrm{~s}$ and a scan rate of $0.05 \mathrm{~V} \mathrm{~s}^{-1}$.

\section{Immunohistochemistry (IHC)}

Double immunofluorescence analysis was performed with brain sections of animals, obtained as previously described [30]. Briefly, animals were anesthetized followed by transcardial perfusion. After this, brains were extracted and postfixed with $4 \%$ PFA and $30 \%$ sucrose solution overnight at $4{ }^{\circ} \mathrm{C}$. Subsequently, $30 \mu \mathrm{m}$ coronal section were obtained using a cryostat. The selected free floating corticalhippocampal section was blocked in $0.1 \mathrm{M}$ phosphate buffer (PB) containing 3\% NGS and $0.1 \%$ Triton $\mathrm{X}-100$ for $1 \mathrm{~h}$ at room temperature. It was then incubated with $A \beta_{1-42}$ primary antibody (H31L21), overnight at $4{ }^{\circ} \mathrm{C}$. Several washes were performed in $0.1 \mathrm{M}$ PB containing $0.1 \%$ Triton $\mathrm{X}-100$. Then, the sections were incubated for $1 \mathrm{~h}$ with a secondary antibody, Alexa Fluor 546 goat anti-rabbit. Nuclei staining was performed using DAPI. Finally, the brain sections were mounted
Fig. 1 Schematic representation of the electrochemical system for detection of $\mathrm{A} \beta_{1-42}$ : a graphene/ rGO SPE-modified with linker (b), antibody (c), BSA (d) and $\mathrm{A} \beta_{1-42}$ peptide (e)

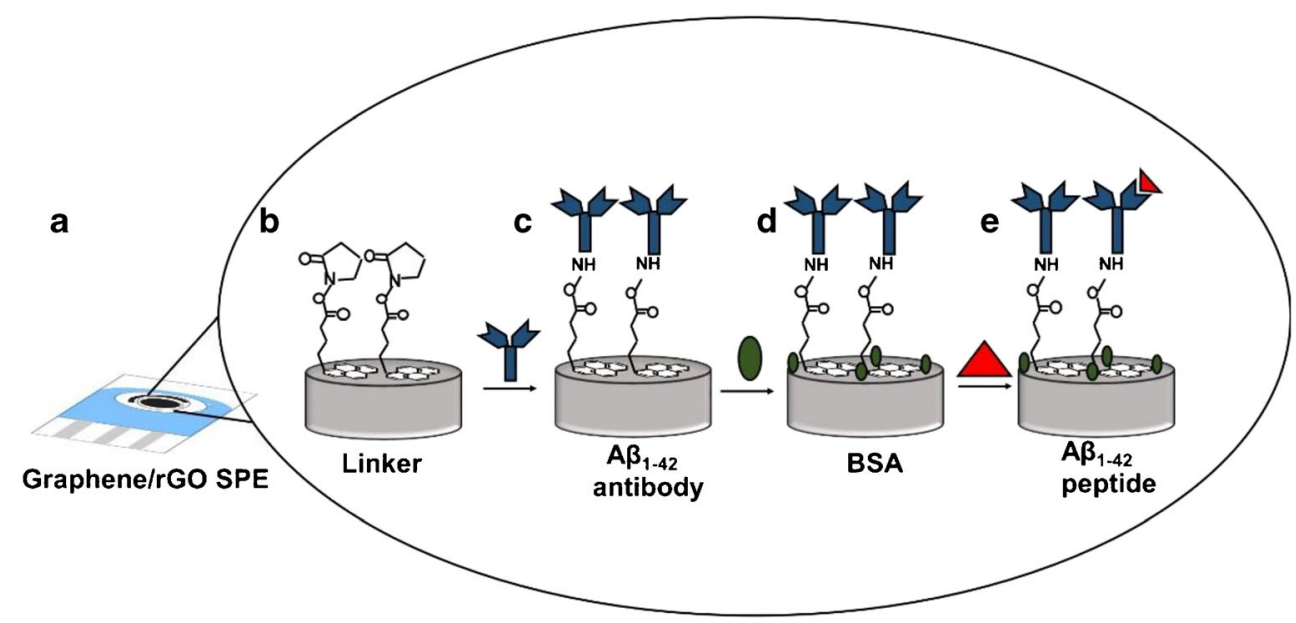


with Vectashield H-1200, and fluorescence microscope images were performed. The images were processed by ImageJ software using stitching method [31].

\section{Results and discussion}

\section{Characterization of the biosensor}

The Raman spectra of graphene and graphene/rGO SPE are shown in Fig. 2. In case of graphene (blue), there is a weak peak around $1346 \mathrm{~cm}^{-1}$ and a strong peak around $1574 \mathrm{~cm}^{-1}$. These can be attributed to the $\mathrm{D}$ and $\mathrm{G}$ band vibrations of graphene with intensity ratio of $\mathrm{D}$ to $\mathrm{G}$ band $\left(\mathrm{I}_{\mathrm{D}} / \mathrm{I}_{\mathrm{G}}\right)$ equal to 0.1 . Further, in case of graphene/rGO (black), wider peaks are observed around $1346 \mathrm{~cm}^{-1}$ and around $1574 \mathrm{~cm}^{-1}$. Here, intensity of $\mathrm{D}$ band is slightly higher than $\mathrm{G}$ band, resulting in a higher $\mathrm{I}_{\mathrm{D}} / \mathrm{I}_{\mathrm{G}}$ ratio of 1.05 . The ratio $\mathrm{I}_{\mathrm{D}} / \mathrm{I}_{\mathrm{G}}$ indicates average distance between defective sites. It increases when the oxygen functionalities on $\mathrm{GO}$ are partly removed with electrochemical reduction [32].

The CV of graphene and graphene/rGO dual-layer SPE were recorded from -0.2 to $+0.5 \mathrm{~V}$ at a scan rate of $50 \mathrm{mV} \mathrm{s}^{-1}$ in $10 \mathrm{mM}\left[\mathrm{Fe}(\mathrm{CN})_{6}\right]^{3-/ 4-}$ and $1 \mathrm{M} \mathrm{KCl}$. The data was acquired at a working potential of $118 \mathrm{mV}$. Figure 3 a shows a comparison in the voltammograms of graphene (blue), graphene/GO (red) and graphene/rGO dual-layer SPE (black). The modification of graphene with GO leads to a decrease in peak current. This is attributed to the long-range broken conjugated network of GO due to a large number of oxygen functional groups. Electrochemical reduction of GO leads to the formation of graphene/rGO dual-layer with higher peak currents compared with only graphene and graphene/GO-modified SPE. This is due to a combination of inherited electroactive sites from rGO and high conductivity of graphene [18].

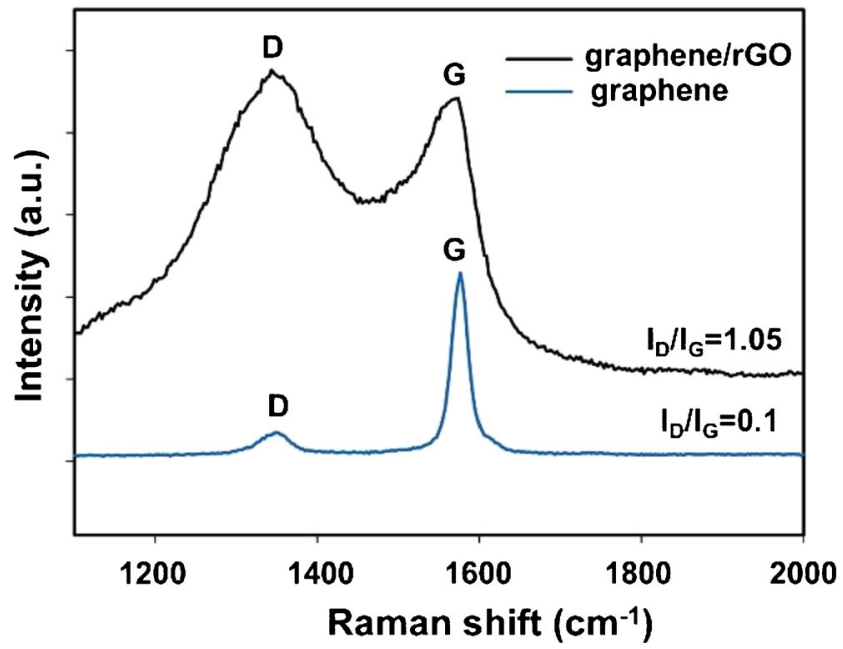

Fig. 2 Raman spectra of graphene (blue) and graphene/rGO (black) duallayer SPE
For the fabrication of biosensor, voltammograms were recorded after each surface modification step. This includes graphene/rGO (blue), linker (red), antibody (black) and BSA (purple) as shown in Fig. 3b. The data was acquired at a working potential of $118 \mathrm{mV}$. It exhibit details relating to the kinetics of charge transfer of the redox probe $\left[\mathrm{Fe}(\mathrm{CN})_{6}\right]^{3}$ - from solution to the electrode. This provides information about the interfacial properties of different layers on the surface. Assembly of linker decreases the anodic peak current $\left(\mathrm{I}_{\mathrm{pa}}\right)$ from 281.033 to $168.628 \mu \mathrm{A}$. This is due to an increase in the electron transfer resistance as it acquires available electroactive sites on rGO. The pyrene moiety binds to the rGO surface via non-covalent bonding ( $\pi-\pi$ interaction), whereas ester group forms an amide bond (covalent bonding) with the antibody [25]. The $\mathrm{I}_{\mathrm{pa}}$ increases to $214.987 \mu \mathrm{A}$ after the immobilization of antibody. This is attributed to the presence of free $\mathrm{NH}^{3+}$ groups (epsilon amines) present on the antibody. These groups accelerate electron transfer between electrode and $\left[\mathrm{Fe}(\mathrm{CN})_{6}\right]^{3-/ 4-}$ system. Immobilization of BSA decreases the $\mathrm{I}_{\mathrm{pa}}$ to $199.534 \mu \mathrm{A}$ as it acquires free functional groups on the surface. This minimizes the chances of nonspecific binding.

Scan rate studies (10 to $200 \mathrm{mV} \mathrm{s}^{-1}$ ) of the modified SPE were performed to study redox process taking place at the surface. Peak to peak separation was found to be dependent on the scan rate indicating a quasi-reversible process. Both cathodic and anodic peak currents increase with an increment in scan rate (Fig. 4a). A linear correlation $\left(R^{2}=0.99\right)$ was obtained for current versus square root of scan rate (Fig. 4b). This is attributed to surface controlled diffusion of $\left[\mathrm{Fe}(\mathrm{CN})_{6}\right]^{3}$ ${ }^{-/ 4}$ with no surface adsorption and is an important requirement for electrochemical biosensors [18]. Randles-Sevcik [25] equation was used for calculating the diffusion coefficient of the redox couple:

$I_{\mathrm{p}}=2 \cdot 69 \times 10^{5} A \sqrt{D}(\sqrt{n})^{3} \sqrt{v} C_{0}$

where $I_{\mathrm{p}}$ is peak current of the electrode (in Ampere), $A$ is the surface area in $\mathrm{cm}^{2}\left(0.126 \mathrm{~cm}^{2}\right), D$ stands for the diffusion coefficient in $\mathrm{cm}^{2} \mathrm{~s}^{-1}, n$ denotes the number of transferred electrons $(n=1), v$ denotes the scan rate $\left(\mathrm{V} \mathrm{s}^{-1}\right)$ and $C_{0}$ is the concentration of the redox couple $\left(10 \mathrm{mM}\left[\mathrm{Fe}(\mathrm{CN})_{6}\right]^{3-/ 4}\right.$ $\left.{ }^{-}\right)$. The value of $\mathrm{D}$ was found to be $1.414 \times 10^{-6} \mathrm{~cm}^{2} \mathrm{~s}^{-1}$ which is in close agreement with the value of $7.26 \times 10^{-6} \mathrm{~cm}^{2} \mathrm{~s}^{-1}$ in the literature [33].

The heterogeneous electron transfer rate constant $\left(K_{\mathrm{S}}\right)$ was calculated for the modified SPE using the Lavrion model:

$\mathrm{Ks}=\frac{m n F v}{R T}$

where $m$ is peak to peak separation $(0.12 \mathrm{~V}), n$ is number of transferred electrons (1), $F$ is the Faraday constant $\left(96,485.34 \mathrm{C} \mathrm{mol}^{-1}\right), v$ denotes scan rate $\left(\mathrm{V} \mathrm{s}^{-1}\right), R$ is 
Fig. 3 Cyclic voltammograms for the modification of SPE with a graphene/rGO (a), graphene (b) and graphene/GO (c); b graphene/ rGO (a), antibody (b), BSA (c) and linker (d), and the CV was taken in $1 \mathrm{M}$ PBS containing $10 \mathrm{mM}\left[\mathrm{Fe}(\mathrm{CN})_{6}\right]^{3-}$ and $1 \mathrm{M} \mathrm{KCl}$ solution at a scan rate of $50 \mathrm{mV} \mathrm{s}^{-1}$

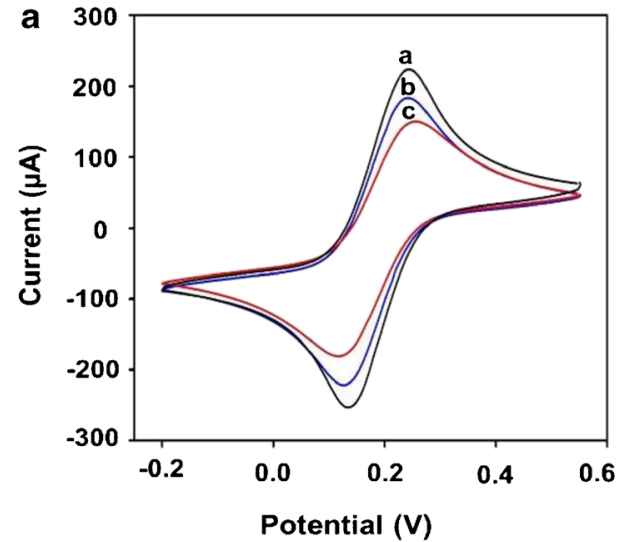

universal gas constant $\left(8.314 \mathrm{~J} \mathrm{~mol}^{-1} \mathrm{~K}^{-1}\right)$ and $T$ is absolute temperature $(298 \mathrm{~K})$. Value of $\mathrm{K}_{\mathrm{s}}$ was calculated to be $0.23 \mathrm{~s}^{-1}$ at a scan rate of $50 \mathrm{mV} \mathrm{s}^{-1}$. This indicates fast electron transfer at the surface of SPE due to large electroactive sites and high conductivity of dual-layer.

\section{Optimization of sensor parameters}

The following parameters were optimized: (a) incubation time of antibody and (b) concentration of linker; respective data and figures are given in the electronic supporting material. The following experimental conditions were found to give best results: (a) concentration of linker, $5 \mathrm{mM}$, and (b) incubation time of antibody, $16 \mathrm{~h}$.

\section{Analytical performance of the biosensor}

Under optimized condition, sensitivity of the biosensor was evaluated against a wide range of concentration from $0.2 \mathrm{pM}$ to $55 \mathrm{nM}$ using DPV. The results were acquired at a working potential of $\sim 180 \mathrm{mV}$ and a scan rate of $50 \mathrm{mV} \mathrm{s}^{-1}$. The current output of biosensor is shown as a function of different concentrations of $A \beta_{1-42}$ in Fig. 5a. The peak current decreased with the increase in concentration. The calibration plot of normalized current $\left(\mathrm{I}_{\mathrm{C}} / \mathrm{I}_{\text {blank }}\right)$ versus concentrations (in $\mathrm{pM}$ ) is shown in Fig. 5b with a linear regression coefficient $\left(R^{2}=0.97\right)$. The error bars were calculated based on 3 replicates of each experiment. The LOD was calculated as $2.398 \mathrm{pM}$ using the following equation:

$\mathrm{LOD}=3.3 *(\mathrm{SD} / \mathrm{SL})$

where $\mathrm{SD}$ is standard deviation of the normalized peak current value of lowest detectable concentration and SL is the slope of calibration plot. The excellent sensing response can be attributed to the sensitive structure of the biosensor. Graphene provides good electrocatalytic activity and electrochemical inertness [18], and rGO provides large electroactive sites. PyrNHS shows strong $\pi-\pi$ interaction with the graphene/rGO dual-layer due to hydrophobic pyrenyl moiety base. Bioactive ester (NHS) group forms strong amide bond with the H31L21 antibody [25] resulting in a target-specific platform. However, fabrication process of the biosensor involves long incubation hours, particularly for antibody immobilization step. In addition, orientation of the antibodies on the surface is difficult to control and can reduce the capture efficiency [34].
Fig. 4 Scan rate studies of modified SPE a voltammograms under varying scan rates a-i (10, $25,50,75,100,125,150,175$ and $200 \mathrm{mV} \mathrm{s}^{-1}$ ); $\mathbf{b}$ anodic (Ipa) and cathodic (Ipc) peak currents versus the square root of corresponding scan rate
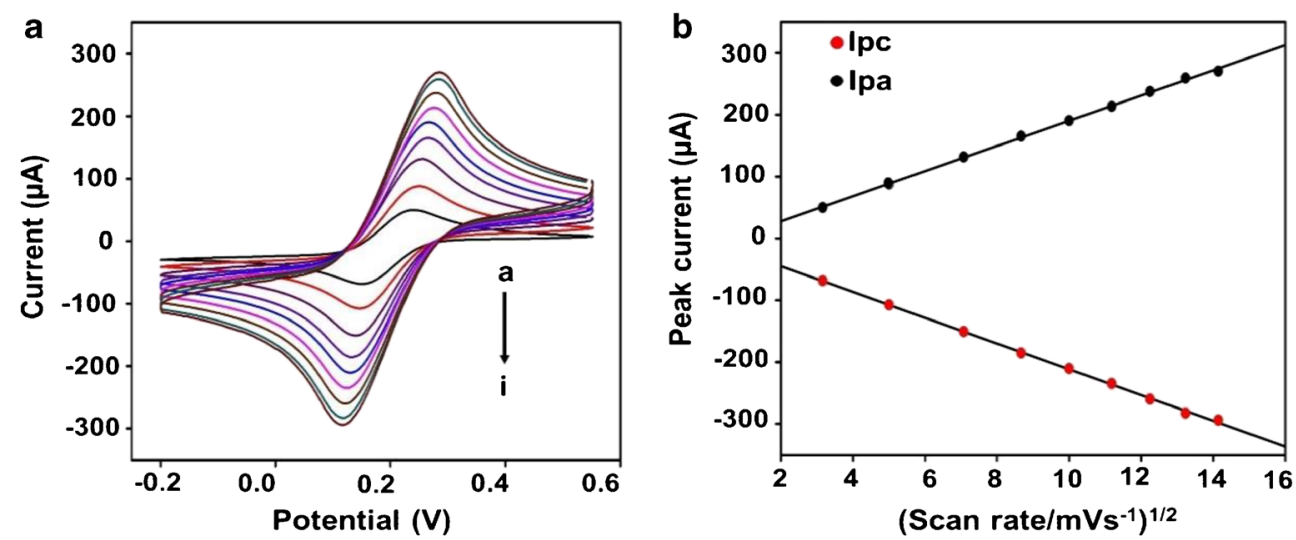
Fig. 5 Analytical performance of the biosensor a DPV curves obtained for the biosensor for detection of different concentration of $\mathrm{A} \beta_{1-42}$ from a-h $(0.2,2,11,50,220,2200,16,600$ and $55,000 \mathrm{pM}$ ); b Calibration plot representing normalized current $\left(\mathrm{I}_{\mathrm{C}} / \mathrm{I}_{\text {blank }}\right)$ of DPV data as a function of $A \beta_{1-42}$ concentration on a logarithmic scale $(n=3)$

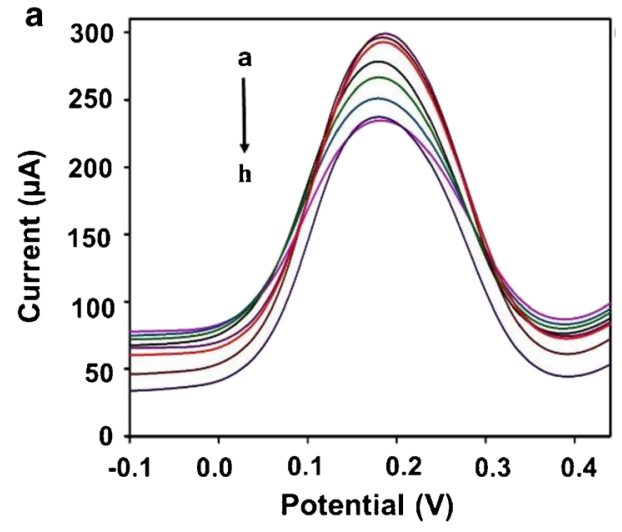

\section{Specificity studies}

The specificity towards $A \beta_{1-42}$ was analysed using the DPV measurements. The modified SPE was incubated in blank (PBS buffer without protein), $50 \mathrm{pM}$ of $\mathrm{A} \beta_{1-42}$ and $500 \mathrm{nM}$ of $A \beta_{1-40}$ and ApoE $\varepsilon 4$ biomarkers. The higher concentration of interfering species was used to ensure the specificity of sensor in complex fluids such as plasma. The bar graphs obtained from the normalized peak currents were plotted as shown in Fig. 6. Only $A \beta_{1-42}$ sample gave a significant decrease, whereas the interfering species were almost equivalent to the blank sample. These results illustrate high specificity of the biosensor towards the $A \beta_{1-42}$ species.

\section{Plasma sample analysis}

Blood-based analysis of $\mathrm{AD}$ biomarkers is emerging as an alternative to the established strategies [35, 36]. This is attributed to the fact that blood sampling technique is less complex and minimally invasive and, therefore, can be applied to large communities. As a result, the

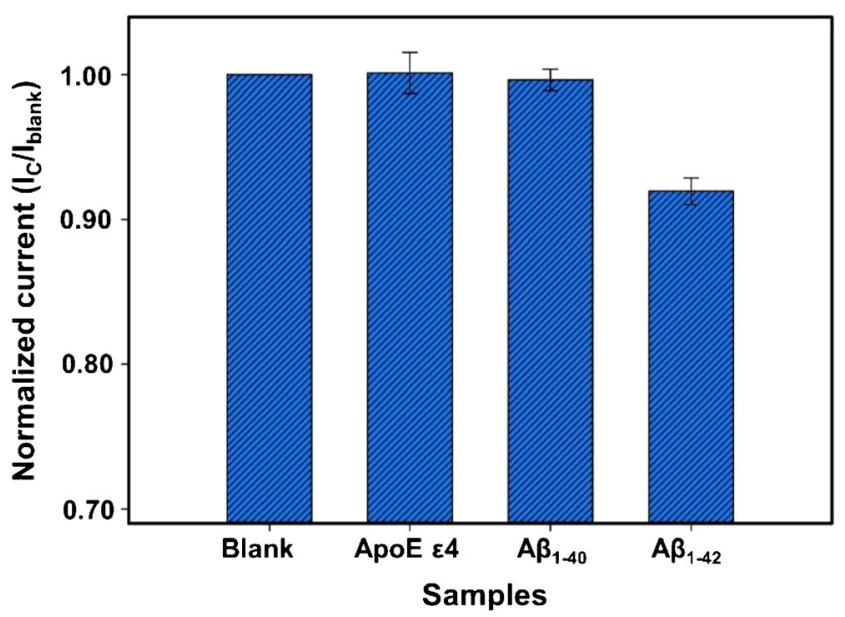

Fig. 6 Specificity of the biosensor for the detection of $50 \mathrm{pM}$ of $\mathrm{A} \beta_{1-42}$ with $500 \mathrm{nM}$ of interfering agents: $\mathrm{A} \beta_{1-40}$ and ApoE $\varepsilon 4$ biosensor was validated with blood plasma (in a series of two experiments) to check the applicability for biofluid analysis. In the first experiment, human plasma was spiked with known concentrations $(50,220,2200$ and $16,600 \mathrm{pM})$ of $\mathrm{A} \beta_{1-42}$. The DPV curves at varying concentration of spiked antigen and its calibration plot are shown in Fig. 7a, b. The sensing platform displayed high linearity in human plasma $\left(R^{2}=0.98\right)$.

In the second experiment, plasma samples obtained from 9 and 12-months-old WT and Tg mice were analysed without any pretreatment. The Tg mouse is an expression of a chimeric mouse and human amyloid precursor protein $(\mathrm{Mo} /$ HuAPP695swe). It also overexpresses a mutant human presenilin 1 (PS1-dE9) gene. Both mutations are associated with early-onset AD. Therefore, these animals are humanized models and produce human $A \beta$ peptide species (e.g. $A \beta_{1-42}$ ). These $A \beta_{1-42}$ species can be detected by specific antibody that either recognize human or mice sequence or both of them [37]. For this reason, human $A \beta_{1-42}$ antibody (H31L21) was used for validation of mice samples using the biosensor. The DPV results shown in Fig. 7c display a much larger shift in peak current for Tg mice as opposed to WT mice. This indicates a higher $A \beta_{1-42}$ concentration in plasma of Tg mice. An age-based study was also performed as shown in Fig. 7d. As seen, a higher normalized current $\left(I_{\mathrm{C}} / I_{\text {blank }}\right)$ is observed in case of 12 months in contrast to 9-month-old mice plasma. This is attributed to the decrease in concentration of $A \beta_{1-42}$ in the plasma of older mice with the progression of $\mathrm{AD}$. However, a larger sample size $(>6)$ is needed for further validation of the biosensor before it can be employed for the determination of patients' sample.

The immunohistochemistry (IHC) data shows a higher accumulation of $A \beta_{1-42}$ in both cortex and hippocampus region. It increases with age for $\mathrm{Tg}$ mice compared with WT mice (Fig. 8). This increase in $A \beta$ plaques burden leads to decrease in plasma $A \beta_{1-42}$ levels observed in Fig. 7 (d) [38]. The correlation in the IHC and sensing data further confirms the reliability of the platform for plasma sample analysis. The magnetic resonance imaging (MRI) data of the 12-month-old mice 
Fig. 7 DPV responses from spiked concentration of $A \beta_{1-42}$ (50 (a), 220 (b), 2200 (c) and 16,600 (d) $\mathrm{pM}$ ) in human plasma (a); calibration plot of normalized current $\left(\mathrm{I}_{\mathrm{C}} / \mathrm{I}_{\text {blank }}\right)$ versus $\log$ of $\mathrm{A} \beta_{1-42}$ concentration (b); DPV responses for detection of WT (b) and $\operatorname{Tg}(\mathbf{c})$ mice compared with blank response (a); an age-based study with the two groups ( 9 and 12 months) of Tg animals (d) ( $n=$ 3)

Fig. 8 IHC data for the progression of $\mathrm{AD}$ pathology: $\mathrm{An}$ increase of human-specific $\mathrm{A} \beta_{(1-}$ 42) (red) aggregation in cortex and hippocampal area; especially in stratum radiatum (SR), stratum lacunosum-moleculare (SLM) and outer portion of the molecular layer of dentate gyrus (OML) and the hilus of the dentate gyrus (DG), from 9 to 12-months-old $\mathrm{Tg}$ compared with $\mathrm{E}$ littermates.

Cornu ammonis (CA1, CA2,

CA3 and hilus (CA4)) are subfield of the hippocampus; nuclei staining is in blue
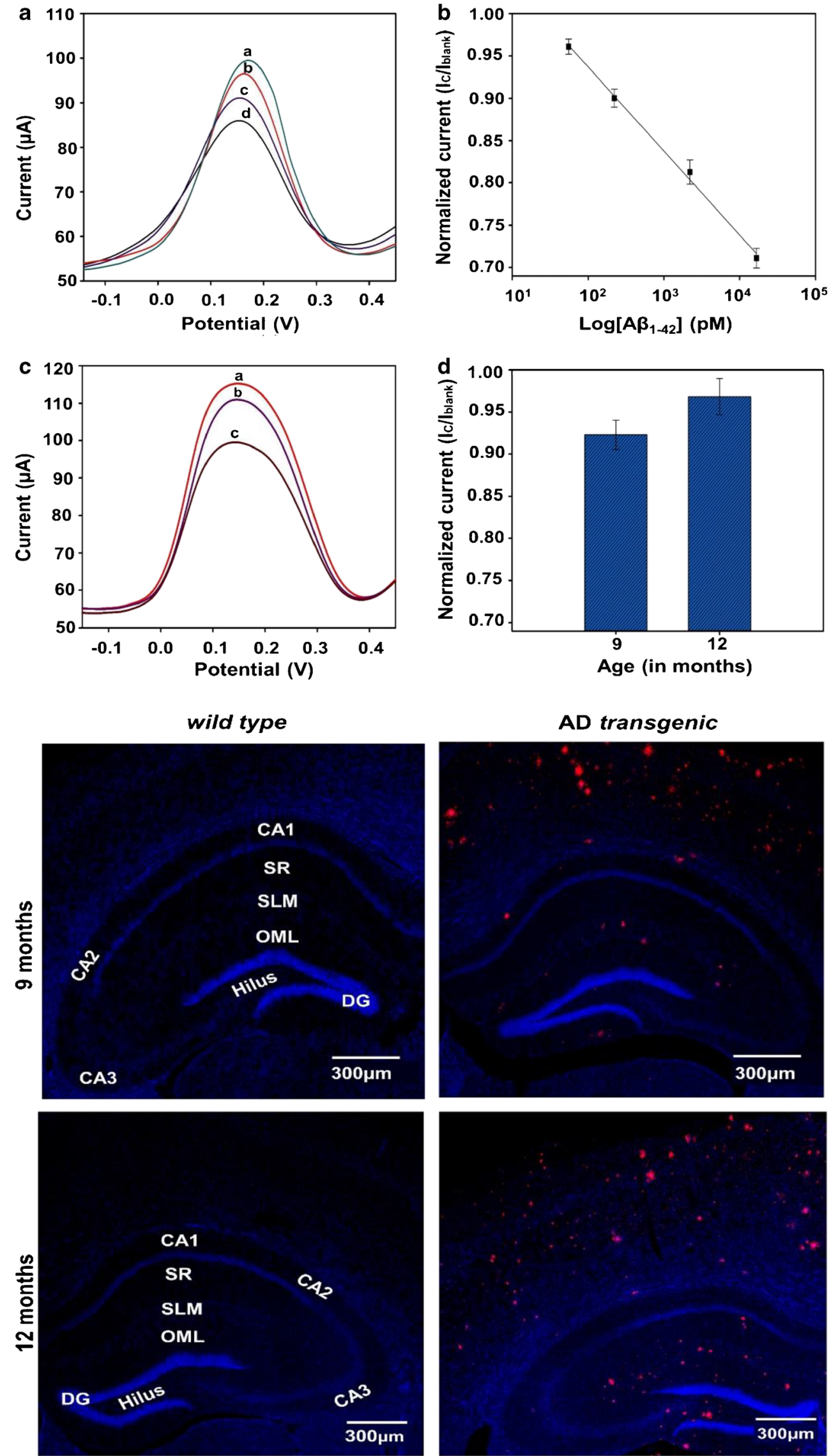
was collected. It also depicts $A \beta$ plaques accumulation in cortex and hippocampus area of the brain (electronic supplementary information Fig. S5).

\section{Conclusion}

In summary, graphene/rGO dual-layer SPE was developed for highly sensitive and label-free detection of $A \beta_{1-42}$. The immobilization of antibodies was achieved via Pyr-NHS molecule. Its pyrene moiety binds to rGO via non-covalent bonding, and ester group forms strong amide bonds with antibody. The sensor depicted high specificity towards $A \beta_{1-42}$ over interfering $A \beta_{1-40}$ and ApoE $\varepsilon 4$ species. It shows excellent performance for human and mice plasma analysis. Agebased study of mice samples exhibited a decrease in levels of $A \beta_{1-42}$ with the disease progression (from 9 to 12 months old). This was attributed to the increased $A \beta_{1-42}$ accumulation in 12-month-old mice shown by the IHC and MRI studies. However, the present study has few limitations. Firstly, the orientation of antibodies on the surface is random which can decrease the capture efficiency and affect the sensitivity of the platform. Secondly, fabrication process of the biosensor is time-consuming due to long incubation hours. Despite this, use of SPEs makes the fabrication process inexpensive and less complex with a possibility of mass production on a large scale. These can also be integrated with point of care devices to develop routine diagnostic tools for AD. For the future work, more comprehensive studies will be conducted using a larger sample size to verify the applicability of biosensor in identifying different stages of AD.

Funding information This work was financially supported by H2020 MSCA-ITN-ETN BBDiag project under grant no. 721281. Scanning electron microscopy was performed by the Plymouth Electron Microscopy Centre (PEMC). X-ray photoelectron microscopy was performed by Harwellxps.

\section{Compliance with ethical standards}

Conflict of interest The authors declare that they have no conflict of interest.

Ethical approval The ethical approval was provided by the "Ethics Committee for Animal Experimentation" of the Instituto de Investigaciones Biomédicas (CSIC-UAM), and experiments were carried out in accordance with European Communities Council Directive (2010/63/EEC) and National regulations (Normative 53/2013).

Open Access This article is licensed under a Creative Commons Attribution 4.0 International License, which permits use, sharing, adaptation, distribution and reproduction in any medium or format, as long as you give appropriate credit to the original author(s) and the source, provide a link to the Creative Commons licence, and indicate if changes were made. The images or other third party material in this article are included in the article's Creative Commons licence, unless indicated otherwise in a credit line to the material. If material is not included in the article's Creative Commons licence and your intended use is not permitted by statutory regulation or exceeds the permitted use, you will need to obtain permission directly from the copyright holder. To view a copy of this licence, visit http://creativecommons.org/licenses/by/4.0/.

\section{References}

1. Balasubramanian K, Kern K (2014) 25th anniversary article: labelfree electrical biodetection using carbon nanostructures. Adv Mater 26(8):1154-1175. https://doi.org/10.1002/adma.201304912

2. Carneiro P, Loureiro J, Delerue-Matos C, Morais S, do Carmo Pereira M (2017) Alzheimer's disease: development of a sensitive label-free electrochemical immunosensor for detection of amyloid beta peptide. Sensors Actuators B Chem 239:157-165. https://doi. org/10.1016/j.snb.2016.07.181

3. Yoo YK, Kim J, Kim G, Kim YS, Kim HY, Lee S, Cho WW, Kim S, Lee S-M, Lee BC (2017) A highly sensitive plasma-based amyloid- $\beta$ detection system through medium-changing and noise cancellation system for early diagnosis of the Alzheimer's disease. Sci Rep 7(1):8882

4. Gagni P, Sola L, Cretich M, Chiari M (2013) Development of a high-sensitivity immunoassay for amyloid-beta 1-42 using a silicon microarray platform. Biosens Bioelectron 47:490-495. https:// doi.org/10.1016/j.bios.2013.03.077

5. Beier HT, Cowan CB, Chou I-H, Pallikal J, Henry JE, Benford ME, Jackson JB, Good TA, Coté GL (2007) Application of surfaceenhanced Raman spectroscopy for detection of beta amyloid using nanoshells. Plasmonics 2(2):55-64. https://doi.org/10.1007/ s11468-007-9027-x

6. Zhao Z, Zhu L, Bu X, Ma H, Yang S, Yang Y, Hu Z (2015) Labelfree detection of Alzheimer's disease through the ADP3 peptoid recognizing the serum amyloid-beta42 peptide. Chem Commun 51(4):718-721. https://doi.org/10.1039/C4CC07037B

7. Yuede CM, Lee H, Restivo JL, Davis TA, Hettinger JC, Wallace CE, Young KL, Hayne MR, Bu G, C-z L, Cirrito JR (2016) Rapid in vivo measurement of $\beta$-amyloid reveals biphasic clearance kinetics in an Alzheimer's mouse model. J Exp Med 213(5):677-685. https://doi.org/10.1084/jem.20151428

8. Ngoc Le HT, Park J, Chinnadayyala SR, Cho S (2019) Sensitive electrochemical detection of amyloid beta peptide in human serum using an interdigitated chain-shaped electrode. Biosens Bioelectron 144:111694. https://doi.org/10.1016/j.bios.2019.111694

9. Dai Y, Molazemhosseini A, Liu CC (2017) In vitro quantified determination of $\beta$-amyloid 42 peptides, a biomarker of neurodegenerative disorders, in PBS and human serum using a simple, cost-effective thin gold film biosensor. Biosensors 7(3):29. https:// doi.org/10.3390/bios7030029

10. Oh J, Yoo G, Chang YW, Kim HJ, Jose J, Kim E, Pyun J-C, Yoo K-H (2013) A carbon nanotube metal semiconductor field effect transistor-based biosensor for detection of amyloid-beta in human serum. Biosens Bioelectron 50:345-350. https://doi.org/10.1016/j. bios.2013.07.004

11. Lien TTN, Takamura Y, Tamiya E, Vestergaard MC (2015) Modified screen printed electrode for development of a highly sensitive label-free impedimetric immunosensor to detect amyloid beta peptides. Anal Chim Acta 892:69-76. https://doi.org/10.1016/j. aca.2015.08.036

12. Hassan Q, Kerman K (2019) Electrochemical approaches for the detection of amyloid- $\beta$, tau, and $\alpha$-synuclein. Curr Opin 
Electrochem 14:89-95. https://doi.org/10.1016/j.coelec.2018.12. 009

13. Henriksen K, O’Bryant SE, Hampel H, Trojanowski JQ, Montine TJ, Jeromin A, Blennow K, Lönneborg A, Wyss-Coray T, Soares H, Bazenet C, Sjögren M, Hu W, Lovestone S, Karsdal MA, Weiner MW (2014) The future of blood-based biomarkers for Alzheimer's disease. Alzheimers Dement 10(1):115-131. https:// doi.org/10.1016/j.jalz.2013.01.013

14. Graff-Radford NR, Crook JE, Lucas J, Boeve BF, Knopman DS, Ivnik RJ, Smith GE, Younkin LH, Petersen RC, Younkin SG (2007) Association of low plasma $A \beta 42 / A \beta 40$ ratios with increased imminent risk for mild cognitive impairment and Alzheimer disease. Arch Neurol 64(3):354-362

15. Lambert J-C, Schraen-Maschke S, Richard F, Fievet N, Rouaud O, Berr C, Dartigues J-F, Tzourio C, Alperovitch A, Buee L (2009) Association of plasma amyloid $\beta$ with risk of dementia: the prospective Three-City Study. Neurology 73(11):847-853

16. Mehta PD, Pirttilä T, Mehta SP, Sersen EA, Aisen PS, Wisniewski HM (2000) Plasma and cerebrospinal fluid levels of amyloid $\beta$ proteins 1-40 and 1-42 in Alzheimer disease. Arch Neurol 57(1): 100-105. https://doi.org/10.1001/archneur.57.1.100

17. Martínez-Morillo E, Hansson O, Atagi Y, Bu G, Minthon L, Diamandis EP, Nielsen HM (2014) Total apolipoprotein E levels and specific isoform composition in cerebrospinal fluid and plasma from Alzheimer's disease patients and controls. Acta Neuropathol 127(5):633-643. https://doi.org/10.1007/s00401-014-1266-2

18. Li B, Pan G, Avent ND, Lowry RB, Madgett TE, Waines PL (2015) Graphene electrode modified with electrochemically reduced graphene oxide for label-free DNA detection. Biosens Bioelectron 72:313-319. https://doi.org/10.1016/j.bios.2015.05.034

19. Geim AK, Novoselov KS (2010) The rise of graphene. In: Nanoscience and Technology: A Collection of Reviews from Nature Journals. World Scientific, pp 11-19

20. Li S-S, Lin C-W, Wei K-C, Huang C-Y, Hsu P-H, Liu H-L, Lu Y-J, Lin S-C, Yang H-W, Ma C-CM (2016) Non-invasive screening for early Alzheimer's disease diagnosis by a sensitively immunomagnetic biosensor. Sci Rep 6(1):25155. https://doi.org/ $10.1038 /$ srep25155

21. Jeong D, Kim J, Chae M-S, Lee W, Yang S-H, Kim Y, Kim SM, Lee JS, Lee JH, Choi J, Yoon DS, Hwang KS (2018) Multifunctionalized reduced graphene oxide biosensors for simultaneous monitoring of structural changes in amyloid- $\beta$ 40. Sensors (Basel) 18(6):1738. https://doi.org/10.3390/s18061738

22. Su Q, Pang S, Alijani V, Li C, Feng X, Müllen K (2009) Composites of graphene with large aromatic molecules. Adv Mater 21(31):3191-3195

23. Wu D, Zhang F, Liu P, Feng X (2011) Two-dimensional nanocomposites based on chemically modified graphene. Chem Eur J 17(39):10804-10812. https://doi.org/10.1002/chem.201101333

24. Georgakilas V, Otyepka M, Bourlinos AB, Chandra V, Kim N, Kemp KC, Hobza P, Zboril R, Kim KS (2012) Functionalization of graphene: covalent and non-covalent approaches, derivatives and applications. Chem Rev 112(11):6156-6214

25. Islam K, Damiati S, Sethi J, Suhail A, Pan G (2018) Development of a label-free immunosensor for clusterin detection as an Alzheimer's biomarker. Sensors 18(1):308
26. Islam K, Suhail A, Pan G (2017) A label-free and ultrasensitive immunosensor for detection of human chorionic gonadotrophin based on graphene FETs. Biosensors 7(3):27

27. Yu Y, Sun X, Tang D, Li C, Zhang L, Nie D, Yin X, Shi G (2015) Gelsolin bound $\beta$-amyloid peptides (1-40/1-42): electrochemical evaluation of levels of soluble peptide associated with Alzheimer's disease. Biosens Bioelectron 68:115-121. https://doi.org/10.1016/j. bios.2014.12.041

28. Dai Y, Molazemhosseini A, Liu CC (2017) In Vitro Quantified Determination of B-Amyloid 42 Peptides, a Biomarker of NeuroDegenerative Disorders, in PBS and Human Serum Using a Simple, Cost-Effective Thin Gold Film Biosensor. Biosensors 7(3):29. https://doi.org/10.3390/bios7030029

29. Golde WT, Gollobin P, Rodriguez LL (2005) A rapid, simple, and humane method for submandibular bleeding of mice using a lancet. Lab Anim 34(9):39-43

30. Luna-Medina R, Cortes-Canteli M, Sanchez-Galiano S, MoralesGarcia JA, Martinez A, Santos A, Perez-Castillo A (2007) NP031112, a thiadiazolidinone compound, prevents inflammation and neurodegeneration under excitotoxic conditions: potential therapeutic role in brain disorders. J Neurosci 27(21):5766-5776

31. Preibisch S, Saalfeld S, Tomancak P (2009) Globally optimal stitching of tiled 3D microscopic image acquisitions. Bioinformatics 25(11):1463-1465

32. Lucchese MM, Stavale F, Ferreira E, Vilani C, Moutinho M, Capaz RB, Achete C, Jorio A (2010) Quantifying ion-induced defects and Raman relaxation length in graphene. Carbon 48(5):1592-1597

33. Baur JE, Wightman RM (1991) Diffusion coefficients determined with microelectrodes. J Electroanal Chem Interfacial Electrochem 305(1):73-81

34. Yang Y, Huang Y, Li C (2019) A reusable electrochemical sensor for one-step biosensing in complex media using triplex-forming oligonucleotide coupled DNA nanostructure. Anal Chim Acta 1055:90-97. https://doi.org/10.1016/j.aca.2018.12.031

35. Jeter CB, Hergenroeder GW, Hylin MJ, Redell JB, Moore AN, Dash PK (2012) Biomarkers for the diagnosis and prognosis of mild traumatic brain injury/concussion. J Neurotrauma 30(8):657670. https://doi.org/10.1089/neu.2012.2439

36. Kim H, Lee JU, Kim S, Song S, Sim SJ (2019) A nanoplasmonic biosensor for ultrasensitive detection of Alzheimer's disease biomarker using a chaotropic agent. ACS Sensors 4(3):595-602. https://doi.org/10.1021/acssensors.8b01242

37. Jankowsky JL, Fadale DJ, Anderson J, Xu GM, Gonzales V, Jenkins NA, Copeland NG, Lee MK, Younkin LH, Wagner SL, Younkin SG, Borchelt DR (2003) Mutant presenilins specifically elevate the levels of the 42 residue $\beta$-amyloid peptide in vivo: evidence for augmentation of a 42-specific $\gamma$ secretase. Hum Mol Genet 13(2):159-170. https://doi.org/10.1093/hmg/ddh019

38. Janelidze S, Stomrud E, Palmqvist S, Zetterberg H, van Westen D, Jeromin A, Song L, Hanlon D, Tan Hehir CA, Baker D, Blennow $\mathrm{K}$, Hansson O (2016) Plasma $\beta$-amyloid in Alzheimer's disease and vascular disease. Sci Rep 6:26801. https://doi.org/10.1038/ srep26801 https://www.nature.com/articles/srep26801\# supplementary-information

Publisher's note Springer Nature remains neutral with regard to jurisdictional claims in published maps and institutional affiliations. 